\title{
Assessment of Thyroid Function and Volume in Hypogonadal Patients
}

\author{
${ }^{1}$ Arpaci Dilek, ${ }^{2}$ Cuhaci Neslihan, ${ }^{2}$ Saglam Fatma, ${ }^{2}$ Ozdemir Didem, ${ }^{2}$ Ersoy Reyhan, ${ }^{2}$ Cakir Bekir. \\ 1 Sakarya Education and Research Hospital, Department of Endocrinology, Sakarya, Turkey \\ 2 Ankara Ataturk Education and Research Hospital, Department of Endocrinology and Metabolism, Ankara, \\ Turkey
}

\section{Abstract}

Background: Hypogonadism is related to additional endocrine abnormalities. Thyroid abnormalities may be common in hypogonadism patients, although this association is not clear.

Objective: In this study, we examined the incidence of thyroid disorders in all types of hypogonadisms.

Methods: A case-control study of 68 hypogonadal patients and 74 age-matched healthy controls from the general population was conducted. Thyroid function, thyroid volume measurements, and presence of thyroid autoantibodies were examined.

Results: The mean body mass index and age of the patient and control groups were similar ( $\mathrm{p}$ $=0.43$ and $p=0.407$, respectively). The thyroid status differed significantly between the patient and control groups $(p=0.002)$. Serum thyroid-stimulating hormone levels were significantly higher in hypogonadal patients than in controls $(\mathrm{p}=0.018)$; however, serum free T4 and free T3 levels did not differ significantly between the two groups $(p=0.29$ and $p=0.63$, respectively). The presence of thyroid autoantibodies (anti-TPO and anti-TG) did not differ significantly between the patient and control groups $(p=0.49$ and $p=0.89$, respectively). There were no differences observed by ultrasonography between the patient and control groups (Table 1). Also, there were no differences in thyroid volumes between two groups (Table 2).

Conclusion: A high incidence of hyperthyroidism and a high incidence of hypothyroidism were observed in hypogonadal patients. 
Table 1. Features of hypogonadal patient and control groups

\begin{tabular}{|c|c|c|c|}
\hline Feature & Patient $(\mathrm{N}=68)$ & Control $(\mathrm{N}=72)$ & P-value \\
\hline Age (years) & $28.5 \pm 9.0$ & $29.2 \pm 8.7$ & 0.407 \\
\hline $\begin{array}{l}\text { Gender } \\
\text { (N; male/female) }\end{array}$ & $57 / 11$ & $64 / 8$ & 0.382 \\
\hline BMI (\%) & $25.9 \pm 4.6$ & $25.4 \pm 2.34$ & 0.435 \\
\hline Free T3(pg/ml) & $3.39 \pm 0.03$ & $3.33 \pm 0.47$ & 0.63 \\
\hline Free T4 (ng/ml) & $1.22 \pm 0.31$ & $1.16 \pm 0.35$ & 0.29 \\
\hline TSH $(\mu \mathrm{IU} / \mathrm{ml})$ & $2.56 \pm 0.97$ & $1.69 \pm 0.85$ & 0.018 \\
\hline $\begin{array}{l}\text { Anti-TPO } \\
\text { (N; positive/negative) }\end{array}$ & $8 / 60$ & $6 / 66$ & 0.5 \\
\hline $\begin{array}{l}\text { Anti-TG } \\
\text { (N; positive/negative) }\end{array}$ & $9 / 59$ & $9 / 63$ & 0.89 \\
\hline Thyroid status (n) & & & \\
\hline Euthyroid & 55 & 71 & 0.002 \\
\hline Hypothyroid & 10 & 1 & \\
\hline Hyperthyroid & 3 & 0 & \\
\hline Thyroid structure (n) & & & \\
\hline
\end{tabular}




\begin{tabular}{|l|l|l|l|}
\hline Normal & 39 & 47 & 0.590 \\
Chronic Thyroiditis & 14 & 11 & \\
Multinodular & 15 & 14 & \\
Goiter & & & \\
\hline
\end{tabular}

BMI, body mass index; TSH, thyroid-stimulating hormone; TPO, thyroid peroxidase; TG, thyroglobulin

Table 2. Thyroid volumes of right and left lobes in hypogonadal patient and control groups

\begin{tabular}{|l|l|l|l|}
\hline & Patient & Control & P-value \\
\hline Right lobe (mL) & $35.48 \pm 19.26$ & $37.48 \pm 15.94$ & 0.51 \\
\hline Left lobe (mL) & $26.97 \pm 13.38$ & $26.88 \pm 11.12$ & 0.26 \\
\hline Total (mL) & $59.67 \pm 30.34$ & $68.02 \pm 43.45$ & 0.22 \\
\hline
\end{tabular}

